\title{
Epistemic and ethical trade-offs in decision analytical modelling
}

\section{A case study of flood risk management in New Orleans}

\author{
Martin Vezér ${ }^{1,2,6}$ • Alexander Bakker ${ }^{1,7}$. \\ Klaus Keller ${ }^{1,3,4} \cdot$ Nancy Tuana ${ }^{2,5}$
}

Received: 25 August 2016 / Accepted: 13 December 2017 / Published online: 28 December 2017

(C) The Author(s) 2017. This article is an open access publication

\begin{abstract}
Designing decision analytical models requires making choices that can involve a range of trade-offs and interactions between epistemic and ethical considerations. Such choices include determining the complexity of a model and deciding what types of risk will be assessed. Here, we demonstrate how model design choices can involve trade-offs between the epistemic benefits of representational completeness and simplicity, which interact with ethical considerations about fairness and human life. We illustrate this point by focusing on modeling studies that assess flood risks in New Orleans, Louisiana. Addressing the ethical and epistemic implications of model design choices can help clarify the scope of factors necessary to inform ethically sound and economically efficient decision-making.
\end{abstract}

Martin Vezér

martin.vezer@sustainalytics.com

1 Earth and Environmental Systems Institute, The Pennsylvania State University, University Park, PA 16802, USA

2 Rock Ethics Institute, The Pennsylvania State University, University Park, PA 16802, USA

3 Department of Geosciences, The Pennsylvania State University, University Park, PA 16802, USA

4 Department of Engineering and Public Policy, Carnegie Mellon University, Pittsburgh, PA 15213, USA

5 Department of Philosophy, The Pennsylvania State University, University Park, PA 16802, USA

6 Present address: Sustainalytics, 215 Spadina Ave., Toronto, ON M5T 2C7, Canada

7 Present address: Rijkswaterstaat, Ministry of Infrastructure and Water Management, Utrecht, Netherlands 


\section{Learning from Katrina}

The effects of Hurricane Katrina exemplify the kinds of ethical issues at stake when addressing concerns about communities exposed to flood risks. After the storm made landfall over southeast Louisiana on 29 August 2005, the failures of levees and floodwalls that were designed to protect New Orleans and its suburbs resulted in the flooding of $80 \%$ of the city, with water depths in some areas reaching $6 \mathrm{~m}$ (Beven et al. 2008). The catastrophe resulted in extensive losses of ethical significance, including loss of life and livelihoods, disruption of communities and life ways, and loss of place. According to official reports, an estimated 1330 people died in the wake of Katrina, while more than 770,000 people were displaced, 300,000 homes were destroyed, and \$96 billion in property damages accrued (The White House 2006).

The tragedy of Katrina highlights the importance of promoting the value of fairness in a region where severe storms are likely to have a disproportionate impact on segments of the population with limited economic or social resources. A reasonable interpretation of the principle of fairness suggests that risks should be distributed so as to mitigate the hazards facing the most vulnerable members of society (Hayenhjelm 2012). Given the damages caused by Katrina, it would seem that certain marginalized groups, including those living in poverty and the elderly, were disproportionately exposed to flood risks. With a poverty rate that was more than twice the national average prior to Katrina, New Orleans was one of the poorest cities in the USA, contributing to the population's vulnerability (Driesen et al. 2005; Masozera et al. 2007). Of the 354,000 people (approximately three quarters of the population) who lived in heavily flooded areas of the New Orleans, $29 \%$ were living in poverty (Gabe et al. 2005; Logan 2006; Sharkey 2007). The death rate among people older than 65 was 15 times higher than that of those younger 65 (Sharkey 2007; Walker 2012).

This paper focuses on two decision analytical models that inform Louisiana's Coastal Protection and Restoration Authority (CPRA). Decision analytical models are representations of complex systems that map objectives and actions to potential outcomes. While each of the models that we will describe offers valuable insights for the purposes of managing flood risks, a more explicit presentation of their epistemic and ethical implications offers a way for decision analysts to account for their design choices. Being explicit about how model design choices involve interactions and trade-offs between epistemic and ethical considerations is an important step in balancing multiple objectives, such as protecting life, communities, and strategic infrastructure. By articulating how such trade-offs occur, one can better understand how a given model addresses a range of objectives or a subset of objectives at the expense of others.

This case study offers insights regarding decision support science more generally. Decision support science is the systematic study of target systems intended to inform decision-makers, typically with respect to complex and uncertain situations, through a range of experiments, observations, and the organization of empirical and theoretical research (Davis et al. 2005). Coastal communities in many regions are increasingly facing exposure to flooding and other hazards driven by climate change (Nicholls and Cazenave 2010; Field 2012; Hallegatte et al. 2013; Insights Report 2016). Deep uncertainties associated with these hazards motivate the development of robust strategies to manage flood risks. Since models are important sources of information for developing and implementing risk management strategies in other contexts as well, the epistemology and ethics of decision analytical modeling is an increasingly relevant area of philosophical research (Tuana 2010; Garner et al. 2016; Bessette et al. 2017). 
This paper contributes an explicit analysis of the interactions and trade-offs between epistemic and ethical considerations about models that help guide policy in coastal Louisiana. Models can better inform decisions when the underlying epistemic and ethical considerations are made clear

In Section 2, we introduce two decision analytical models that inform the CPRA. In Section 3, we explain how these models involve epistemic trade-offs. In Section 4, we show how these epistemic trade-offs interact with ethical considerations. In Section 5, we summarize and discuss our findings.

\section{Two models for assessing flood risks Costal Louisiana}

In 2005, legislators restructured the States Wetland Conservation and Restoration Authority to form the CPRA, which has the mandate "to develop, implement, and enforce a comprehensive coastal protection plan" (First Extraordinary Session 2005). Since then, the CPRA has published quarterly, annual, and 5-year reports (CPRA 2016). These reports draw on studies that apply several models, including the Coastal Louisiana Risk Assessment model (CLARA) (Groves et al. 2014) and what we refer to here as the Dutch Perspective Model (DPM) (Jonkman et al. 2009a).

CLARA and DPM differ in several respects. On the one hand, DPM provides rough estimates of the cost-effectiveness of investing in levee heightening as a flood protection measure. Based on the pioneering study of David van Dantzig (1956), DPM is an economic optimization model that compares the investment costs of levee heightening with expected losses due to flooding. Apart from its short run time, its simplicity and transparent setup allow for the incorporation of additional considerations beyond the parameters of the original model, such as the effect of accelerated sea-level change (Wong et al. 2017a).

CLARA, on the other hand, informs assessments about the efficacy of multiple projects intended to reduce the flood risk of the entire system by modeling multiple flood protection components, including levees, floodwalls, sediment transport, marsh creation, pumping, and drainage. This model produces data relevant for addressing a diverse set of decision criteria, such as protecting strategic and historic assets. CLARA incorporates information about different flood protection system configurations and future environmental and economic uncertainties to project flood depths and associated damages that could result from different types of storms and protection measures over a 50-year timeframe (Groves et al. 2014).

\section{Epistemic trade-offs}

Design differences between CLARA and DPM exemplify a trade-off between two epistemic advantages: representational completeness and simplicity. While representational completeness is the level detail, resolution and number of parts of captured by a model, simplicity is the quality of having relatively few (supposedly most relevant) components, which may enhance transparency and adjustability. Whereas representational completeness contributes vital details relevant to conducting decision analysis, the advantages of simplicity allow for critical user involvement, which is also key to informed decision-making. CLARA and DPM differ in their spatial resolution as well as processes they represent. These model differences are expected to drive divergences in their accuracy and precision, although the direction is, at this time, unclear. Including more processes can increase or decrease the precision 
and accuracy depending on factors such as the available information to calibrate the model, model structural errors, or differences in the ability to perform the required computation to estimate the model parameters with the associated uncertainty.

Comparing CLARA and DPM in terms of their scope, resolution, and number of parameters demonstrates the trade-off between completeness and simplicity. Researchers who design and apply these models define their targets in different ways, but insofar as both models represent flood protection systems in Coastal Louisiana, CLARA is more representationally complete than DPM, and DPM is simpler than CLARA.

The scope and resolution of CLARA are much greater than the scope and resolution of DPM. CLARA represents the entire coastal region of Louisiana at a resolution that estimates flood depths and other information about more than 90,000 locations and 35,000 census tracts (Groves et al. 2016). DPM represents an area containing Orleans, Jefferson, and St. Bernard, and estimates potential damage values averaged within each polder surrounding these parishes (Dijkman 2007; Jonkman et al. 2009a).

CLARA is organized into a series of submodules, which incorporate data about different potential flood depths, flooding mechanisms, and the interior of the protection systems. This model also incorporates an economic module that draws on estimates of asset valuations and inventories, potential economic damages, storm surges, wave characteristics, rainfall volumes, and vulnerability to flood depth (Fischbach et al. 2012; Peyronnin et al. 2013; Meselhe et al. 2015). In contrast, DPM only includes estimates of the probability and economic damage in case a levee overtops, a discount factor, sea-level rise, and the investment costs associated with increasing levee height (Dijkman 2007; Jonkman et al. 2009a).

One advantage of increasing the spatial resolution and representational completeness in the case of CLARA is its capacity to differentiate flood risks by location and storm exposure. In examining five regions of New Orleans-St. Charles-Jefferson East Bank, St. Bernard, Orleans Main, New Orleans East, and West Bank-Johnson et al. (2015) find that, with the current hurricane and storm damage risk reduction system and economic redevelopment measures, these areas are protected against storm surges of approximately the 200-year return period, under a scenario in which the probability of levee failure as a function of overtopping rates is low (USACE 2013; Johnson et al. 2013). For more severe storm surges, CLARA projects flood depths increasing in New Orleans East and St. Bernard. Projecting a similar scenario out to 2065, CLARA suggests Orleans Main and the West Bank communities would maintain a 100-year protection level, whereas New Orleans East would be exposed to flooding at higher frequencies (Johnson et al. 2015).

While the completeness of CLARA offers the epistemic benefits of a detailed representation, it also corresponds to an increase in model complexity; it contains a large number of interacting parts, which involve positive and negative feedbacks that create non-linear responses. Increasing the scope, resolution and parameters of a model that represents a complex system may, therefore, entail a trade-off between completeness and the epistemic advantages associated with simplicity (Fig. 1).

Completeness and simplicity do not necessarily trade-off against one another, given that simple models can be relatively complete representations of simple systems. However, simple models of complex systems offer the epistemic advantages of transparency, accessibility, and computational efficiency at the expense of completeness. In an ideal case, a model would be maximally simple yet representative enough to inform decision-making for a given task, such as assessing particular kinds of flood risks.

The advantages of DPM's simplicity include its relatively short development and run times, and its being easily reproducible, relatively easy to understand, computationally inexpensive and amenable to modification for other applications. Such features may promote 


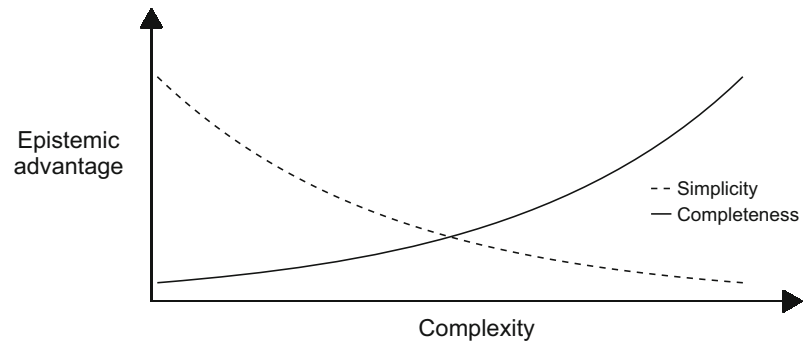

Fig. 1 Modeling complex target systems can involve a trade-off between the epistemic advantages of simplicity and representational completeness

user-producer interaction, which is instrumental for incorporating relevant ethical considerations, which we describe below.

The reproducibility and versatility of DPM are illustrated by the publication of the model's simple source code (Applegate et al. 2016; Wong et al. 2017b) and the range of other contexts in which it has been applied. Eijgenraam, for example, considers the base model of DPM (i.e., "the Van Dantzig model") under condition of an improved flood defence system, changing economic growth, and sea-level rise (Eijgenraam 2006). Other studies have applied the model to flood risk analysis of areas in Vietnam (Mai et al. 2008), the Netherlands, and Japan (Jonkman et al. 2004).

\section{Ethical interactions}

Consequences associated with risk are often expressed in monetary terms. CLARA estimates flood risk in part by assigning a value on each census block; damage is a function of the economic value of an inventory of assets, such as homes, roads, agricultural buildings, and crops (Groves et al. 2014). Similarly, applications of DPM place monetary values on aggregated economic assets, aiming to balance risks to assets and investments in flood protection (Dijkman 2007).

CLARA and DPM can also be applied to address risks associated with ethical considerations. An ethical upshot of CLARA's completeness is its potential to help address concerns related to the value of fairness. One way of understanding the idea of fairness is as a balance between equality and justifying any deviations from equality with an account of how particular inequalities provide benefits to the least advantaged (Rawls 2009; Hayenhjelm 2012). Measures of social vulnerability focus on the socioeconomic features of a community that affect its capacity to prepare, respond, cope, and recover from a hazard event (Finch et al. 2010). From this perspective, decisions about flood risk management are fair only if they provide equal protection or if any deviation from equal protection benefits the most vulnerable members of society.

Illustrating how CLARA can be applied to address consideration about fairness, Groves et al. (2016) examine the efficacy of residential structure elevation projects for vulnerable households, which are measured in terms of their being at low to moderate income levels or having experienced repetitive losses. They explore the relationships among projected flood depths, socioeconomic data, and potential benefits and costs of elevating structures in the parishes of Lafourche, Terrebonne, and Palquemines. The broad geographical scope of CLARA enables the study of different regions, and its high resolution allows researchers to 
compare how elevation projects may protect socially vulnerable communities in different census block groups.

Although the relative completeness of CLARA offers the advantage of accounting for differential risks in different areas of the target system, its complexity makes it more computationally expensive, less transparent, and less amenable to reproducibility and scrutiny than are simpler models such as DPM. Comparing CLARA and DMP illustrates how choices to design a model as more or less complete can imply a trade-off between the epistemic benefits of simplicity and ethical considerations about ways in which people are disproportionately exposed to risk.

An ethical upshot of the simplicity of DPM is its amenability to an examination of the assumption that direct economic damage serves as a proxy for other risks, such as loss of life. The epistemic advantages associated with DPM's simplicity-its transparency and amenability to being reproduced and modified-make implementing changes efficient and quick to assess. To demonstrate this point, we compare the output of DPM with estimates of risk to life, making explicit the implied thresholds of tolerable risks related to investments in flood protection, evacuation rates, and individual mortality risk (Fig. 2).

This comparison shows the potential combined outcomes of investing in levee heightening, promoting the evacuation efforts needed to protect economic assets, and meeting different conventional standards of acceptable risk to life in the most flood-prone areas (Jonkman et al. 2009a, b; Miller et al. 2015). This type of analysis would be less straightforward with a complex model like CLARA because the coupling of a risk to life module
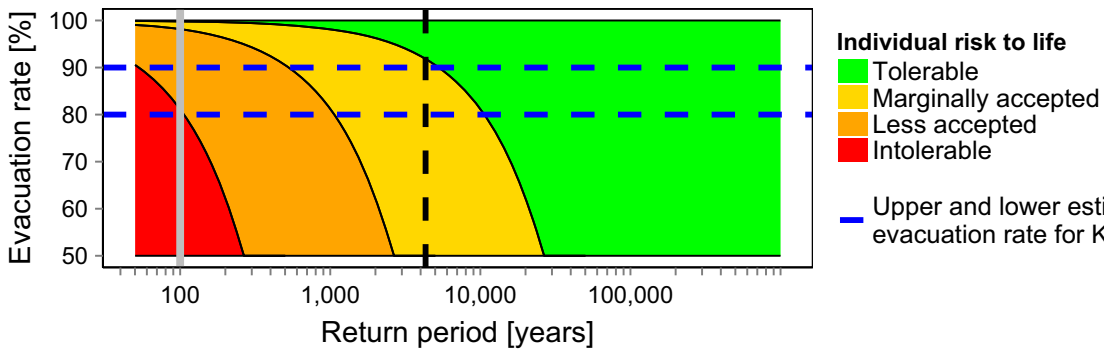

Upper and lower estimates of evacuation rate for Katrina

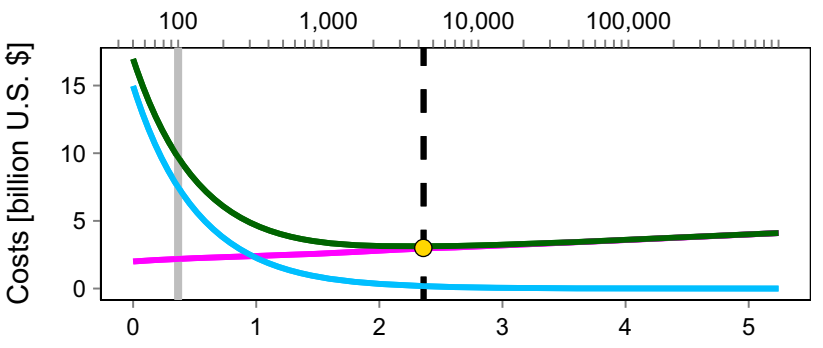

$$
\begin{aligned}
& \text { - Investment } \\
& \text { - Risk } \\
& - \text { Total costs } \\
& -100-y r \text { return level } \\
& - \text { Economic optimal level } \\
& \text { Optimal point }
\end{aligned}
$$

Levee heightening compared to pre-Katrina levels [meters]

Fig. 2 The upper panel depicts standard acceptance rates of individual risk to life (from green to red) for different combinations of evacuation rate ( $y$-axis) and flood protection level ( $x$-axis) (Miller et al. 2015). The lower panel depicts the results of DPM applied to New Orleans Northern levee ring (Jonkman et al. 2009a). Investment costs (pink line) and corresponding risk (light blue line) are functions of levee heightening compared to the pre-Katrina heights (lower $x$-axis). The total cost (green line) is the sum of the investment and risk, which is at a minimal point at a levee heightening of approximately $2 \mathrm{~m}$ (yellow dot) and corresponds to a flood probability of 1:4000-5000 years (upper $x$-axis) 
to CLARA is more complicated and practically infeasible without involvement of official CLARA developers. Furthermore, the relatively longer run times of CLARA prohibit a complete exploration of the relationship between protection level and risk to life.

The economically optimal levee height estimated by DPM (vertical black dashed line) corresponds to a "tolerable" individual risk to life $\left(<10^{-6} \mathrm{yr}^{-1}\right)$ under a scenario with an evacuation rate of over $92 \%$ of the population. According to this metric, "tolerable" individual risk to life is $<10^{-6} \mathrm{yr}^{-1}$, "marginally accepted" individual risk to life is $<10^{-5} \mathrm{yr}^{-1}$, "less accepted" individual risk to life is $<10^{-4} \mathrm{yr}^{-1}$, and "intolerable" individual risk to life is $>10^{-4} \mathrm{yr}^{-1}$. For comparison, the Dutch water law updated in January 2017 demands a risk to life of $<10^{-5} \mathrm{yr}^{-1}$, though most locations aim for higher levels of safety.

The 100-year flood protection level (solid grey line), which this application of DPM identifies as economically suboptimal, corresponds to a less accepted individual risk to life under a scenario with less than $98 \%$ evacuation rate. In this regard, the 100 -year protection level presents an intolerable individual risk to life under a scenario with a less than an $81 \%$ evacuation rate.

The simplicity of DPM also implies an omission of additional factors, such as alternative strategies of flood risk management. Explicitly, DPM focuses on only one type of flood risk management strategy: levee heightening. Other strategies that are left out include migration, evacuation, marshland stabilization, and building social resilience. These strategies pertain to a range of ethical issues regarding sense of place and security, which the United Nations Framework Convention on Climate Change lists among the important non-economic losses that should be addressed by climate change policy (Fankhauser et al. 2014).

\section{Addressing epistemic and ethical factors in decision support science}

This paper has shown how, in developing decision analytical models, epistemic considerations, such as whether to develop a complex or simple model, can have ethical implications, including determining the extent to which a model can address concerns about fairness and human life. CLARA and DPM exhibit these trade-offs, and explicitly accounting for them may further motivate moving beyond assessments that focus narrowly on economic impacts as it shows how decision support science can focus on the wider range of ethical issues of public interest. Analysts developing models may better support decision-makers by articulating the roles and interactions of epistemic and ethical considerations that go into models.

In its review of the US Army Corps of Engineers Louisiana Coastal Protection and Restoration Program (USACE 2009), the National Research Council cites the economic analysis of the Dutch Perspective as providing economic justification for increased flood protection standards: "Storm surge protection for the City of New Orleans should be designed for a hurricane storm surge event with an expected return interval of 400 to 1000 years" (LACPR 2009). Further integrating the issues of human life, community and fairness in decision analytical modeling studies may well strengthen this recommendation.

Acknowledgements We thank Patrick Applegate, Doug Bessette, Chris Forest, Jordan Fischbach, Murali Haran, David Johnson, Rob Lempert, Rob Nicholas, Perry Oddo, and the anonymous reviewers for invaluable input. This work was partially supported by the National Science Foundation through the Network for Sustainable Climate Risk Management (SCRiM) under NSF cooperative agreement GEO-1240507, the Penn State Center for Climate Risk Management and the Penn State Rock Ethics Institute. Any opinions, findings, conclusions or recommendations expressed in this material are those of the authors and do not necessarily reflect the views of the funding entities. 
Open Access This article is distributed under the terms of the Creative Commons Attribution 4.0 International License (http://creativecommons.org/licenses/by/4.0/), which permits unrestricted use, distribution, and reproduction in any medium, provided you give appropriate credit to the original author(s) and the source, provide a link to the Creative Commons license, and indicate if changes were made.

\section{References}

Applegate P, Bakker A, Keller K (2016) Lab \#4: what is the economically "optimal” height of flood protection structures? The Van Dantzig (1956) example. In: Applegate P, Keller K (eds) Risk analysis in the earth sciences. Leanpub. https://leanpub.com/raes. Accessed 31 July 2016

Bessette DL, Mayer LA, Cwik B, Vezér M, Keller K, Lempert RJ, Tuana N (2017) Building a valuesinformed mental model for New Orleans climate risk management. Risk Analysis

Beven JL, Avila LA, Blake ES, Brown DP, Franklin JL, Knabb RD, Pasch RJ, Rhome JR, Stewart SR (2008) Atlantic hurricane season of 2005. Mon Weather Rev 136(3):1109-1173. https://doi.org/10.1175/2007mwr2074.1

CPRA (2016) Costal protection and restoration authority, reports. http://coastal.la.gov/. Accessed 31 July 2016

Davis PK, Kulick J, Egner M (2005) Implications of modern decision science for military decisionsupport systems. Rand Corporation. https:/www.rand.org/content/dam/rand/pubs/monographs/2005/ RAND_MG360.pdf. Accessed 31 July 2016

Dijkman J (ed.) (2007) A Dutch perspective on Coastal Louisiana: flood risk reduction and landscape stabilization. Technical report, Netherlands Water Partnership, Delft, the Netherlands. http://www.dtic.mil/ docs/citations/ADA473780. Accessed 31 July 2016

Driesen DM, Flournoy A, Foster S, Gauna E, Glicksman RL, Gonzalez CG, Gottlieb DJ, Hornstein DT, Kysar DA, McGarity TO et al (2005) An unnatural disaster: the aftermath of Hurricane Katrina. Center for Progressive Reform Publication. http://digitalcommons.law.umaryland.edu/cgi/viewcontent.cgi? article $=2385 \&$ context $=$ fac_pubs. Accessed 31 July 2016

Eijgenraam CJ (2006) Optimal safety standards for dike-ring areas. Technical report, CPB-Central Plan Bureau. http://coastal.la.gov/resources/library/reports/. Accessed 31 July 2016

Fankhauser S, Dietz S, Gradwell P (2014) Non-economic losses in the context of the United Nations Framework Convention on Climate Change work programme on loss and damage. http://eprints.lse.ac.uk/ 64554/1/Fankhauser-Dietz-Gradwell-Loss-Damage-final.pdf. Accessed 31 July 2016

Field CB (2012) Managing the risks of extreme events and disasters to advance climate change adaptation: special report of the Intergovernmental Panel on Climate Change. Cambridge University Press. https:// www.ipcc.ch/pdf/special-reports/srex/SREX_Full_Report.pdf. Accessed 31 July 2016

Finch C, Emrich CT, Cutter SL (2010) Disaster disparities and differential recovery in New Orleans. Popul Environ 31(4):179-202. https://doi.org/10.1007/s11111-009-0099-8

First Extraordinary Session (2005) Act 8 part ii, section 213.1. Technical report, Louisiana State Legislature. https://www.legis.la.gov/legis/SessionInfo/SessionInfo_161ES.aspx. Accessed 31 July 2016

Fischbach JR, Johnson DR, Ortiz DS, Bryant BP, Hoover M, Ostwald J (2012) Coastal Louisiana risk assessment model: technical description and 2012 coastal master plan analysis results. Santa Monica, California: RAND Corporation, 118p. https://www.rand.org/content/dam/rand/pubs/technical_reports/ 2012/RAND_TR1259.pdf. Accessed 31 July 2016

Gabe T, Falk G, McCarty M, Mason VW (2005) Hurricane Katrina: social-demographic characteristics of impacted areas. CRS Report for Congress. http://www.tidec.org/sites/default/files/uploads/crsrept.pdf. Accessed 31 July 2016

Garner G, Reed P, Keller K (2016) Climate risk management requires explicit representation of societal trade-offs. Clim Chang 134(4):713-723. https://doi.org/10.1007/s10584-016-1607-3

Groves DG, Fischbach JR, Knopman D, Johnson DR, Giglio K (2014) Strengthening coastal planning: how coastal regions could benefit from Louisiana's planning and analysis framework. Rand Corporation. https://www.rand.org/pubs/research_reports/RR437.readonline.html. Accessed 31 July 2016

Groves DG, Kuhn K, Fischbach J, Johnson DR, Syme J (2016) Analysis to support Louisiana's flood risk and resilience program and application to the national disaster resilience competition. RAND Corporation. https:/www.rand.org/content/dam/rand/pubs/research_reports/RR1400/RR1449/RAND_RR1449. pdf. Accessed 31 July 2016

Hallegatte S, Green C, Nicholls RJ, Corfee-Morlot J (2013) Future flood losses in major coastal cities. Nat Clim Chang 3(9):802-806. https://doi.org/10.1038/nclimate1979 
Hayenhjelm DM (2012) What is a fair distribution of risk? In: Roeser S, Hillerbrand R, Sandin P, Peterson M (eds) Handbook of risk theory. Springer, Netherlands, pp 909-929. https://doi.org/10.1007/978-94007-1433-5_36

Insights Report (2016) The global risks report. Technical report, World Economic Forum, within the framework of The Global Competitiveness and Risks Team. http://www3.weforum.org/docs/GCR2016-2017/ 05FullReport/TheGlobalCompetitivenessReport2016-2017_FINAL.pdf. Accessed 31 July 2016

Johnson DR, Fischbach JR, Ortiz DS (2013) Estimating surge-based flood risk with the coastal Louisiana risk assessment model. J Coast Res 67(sp1):109-126. https://doi.org/10.2112/si_67_8

Johnson DR, Fischbach JR, Kuhn K (2015) Current and future flood risk in greater New Orleans. The Data Center. http://www.datacenterresearch.org/reports_analysis/flood-risk/. Accessed 31 July 2016

Jonkman S, Kato F, Vrijling J (2004) A comparison of flood risk assessment practices in the Netherlands and Japan. Coast Eng Conf 29(3):3049. https://doi.org/10.1142/9789812701916_0246

Jonkman S, Kok M, Van Ledden M, Vrijling J (2009a) Risk-based design of flood defence systems: a preliminary analysis of the optimal protection level for the new orleans metropolitan area. J Flood Risk Manage 2(3):170-181. https://doi.org/10.1111/j.1753-318x.2009.01036.x

Jonkman S, Maaskant B, Boyd E, Levitan M (2009b) Loss of life caused by the flooding of New Orleans after Hurricane Katrina: analysis of the relationship between flood characteristics and mortality. Risk Anal 29(5):676-698. https://doi.org/10.1111/j.1539-6924.2008.01190.x

LACPR (2009) LACPR program committee, final report from the NRC committee on the review of the Louisiana coastal protection and restoration (LACPR) Program. National Academies Press. http://link. sailsinc.org/portal/Final-report-from-the-NRC-Committee-on-the-Review/MUk79ydpZ8g/. Accessed 31 July 2016

Logan JR (2006) The impact of Katrina: race and class in storm-damaged neighborhoods. Brown University 16. http://wps.ablongman.com/wps/media/objects/12936/13246811/pdf/Report_2.pdf. Accessed 31 July 2016

Mai CV, Van Gelder P, Vrijling JK, Mai TC (2008) Risk analysis of coastal flood defences: a Vietnam case. In: 4th international symposium on flood defence "Managing flood risk, reliability and vulnerability", Toronto, Canada, 6-8 May 2008. Institute for Catastrophic Loss Reduction. https://www.kivi.nl/uploads/media/57e59dc727144/Risk\%20analysis\%20of\%20coastal\%20flood $\% 20$ defences\%20-\%20A\%20Vietnam\%20case\%20(2008).pdf. Accessed 31 July 2016. Accessed 31 July 2016

Masozera M, Bailey M, Kerchner C (2007) Distribution of impacts of natural disasters across income groups: a case study of New Orleans. Ecol Econ 63(2):299-306. https://doi.org/10.1016/j.ecolecon.2006.06.013

Meselhe E, Reed DJ, Grace AO (2015) 2017 coastal master plan: Appendix C: modeling. Version I. (p. 120). Technical report, Coastal Protection and Restoration Authority. Baton Rouge, Louisiana. http://coastal. la.gov/wp-content/uploads/2016/05/Appendix-C-Ch123_052516.pdf. Accessed 31 July 2016

Miller A, Jonkman SN, Ledden MV (2015) Risk to life due to flooding in post-Katrina New Orleans. Nat Hazards Earth Syst Sci 15(1):59-73. https://doi.org/10.5194/nhess-15-59-2015

Nicholls RJ, Cazenave A (2010) Sea-level rise and its impact on coastal zones. Science 328(5985):15171520. https://doi.org/10.1126/science. 1185782

Peyronnin N, Green M, Richards CP, Owens A, Reed D, Chamberlain J, Groves DG, Rhinehart WK, Belhadjali K (2013) Louisiana's 2012 coastal master plan: overview of a science-based and publicly informed decision-making process. J Coast Res:1-15. https://doi.org/10.2112/si_67_1.1

Rawls J (2009) A theory of justice. Harvard University Press, Cambridge

Sharkey P (2007) Survival and death in New Orleans: an empirical look at the human impact of Katrina. J Black Stud 37(4):482-501. https://doi.org/10.1177/0021934706296188

The White House (2006) The federal response to hurricane. Katrina: lessons learned. Technical report, USA Government Record. http://www.washingtonpost.com/wp-dyn/content/article/2006/02/23/ AR2006022300531.html. Accessed 31 July 2016

Tuana N (2010) Leading with ethics, aiming for policy: new opportunities for philosophy of science. Synthese 177(3):471-492. https://doi.org/10.1007/s11229-010-9793-4

USACE (2009) U.S. army corps of engineers, Louisiana coastal protection and restoration (LACPR) final technical report. Technical report, New Orleans District Mississippi Valley Division. http://www.mvn. usace.army.mil/Portals/56/docs/environmental/LaCPR/LACPRFinalTechnicalReportJune2009.pdf. Accessed 31 July 2016

USACE (2013) The U.S. army corps of engineers, revised programmatic environmental impact statement: Morganza to the gulf of Mexico, Louisiana. Technical report, Mississippi Valley Division, New Orleans District. http://www.mvn.usace.army.mil/Portals/56/docs/PD/Projects/MTG/ FinalRevisedProgrammaticEISMtoG.pdf. Accessed 31 July 2016 
Van Dantzig D (1956) Economic decision problems for flood prevention. Econometrica 24(3):276-287. https://doi.org/10.2307/1911632

Walker G (2012) Environmental justice: concepts, evidence and politics. Routledge, Evanston

Wong TE, Bakker AM, Keller K (2017a) Impacts of Antarctic fast dynamics on sea-level projections and coastal flood defense. Climatic Change (144):347-364. https://doi.org/10.1007/s10584-017-2039-4

Wong TE, Bakker AM, Ruckert K, Applegate P, Slangen A, Keller K (2017b) Brick v0. 2, a simple, accessible, and transparent model framework for climate and regional sea-level projections. Geosci Model Dev 10(7). https://doi.org/10.5194/gmd-2016-303 